\title{
Long Saphenous Vein
}

National Cancer Institute

\section{Source}

National Cancer Institute. Long Saphenous Vein. NCI Thesaurus. Code C33004.

A long superficial vein originating from the dorsal vein at the big toe and the dorsal

venous arch of the foot and extending up the inner leg to empty into the femoral artery

in the groin area. 